\title{
Study the efficacy of repetitive trans cranial magnetic stimulation on a sample of resistant schizophrenic patients with positive and negative symptoms
}

Omar Ashraf Aglan ${ }^{1 *}$ M.B.B.Ch; Amgad Ahmed Gabr ${ }^{1}$ MD; Mohamed Khaled Helmy ${ }^{1}$ MD

*Corresponding Author:

Omar Ashraf Aglan

\section{omaraglan20@gmail.com}

Received for publication October 07, 2021; Accepted December 25, 2021; Published online December 25,2021.

Copyright The Authors published by Al-Azhar University, Faculty of Medicine, Cairo, Egypt. Users have the right to read, download, copy, distribute, print, search, or link to the full texts of articles under the following conditions: Creative Commons AttributionShare Alike 4.0 International Public License (CC BY-SA 4.0).

doi: 10.21608/aimj.2021.95364.1576

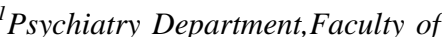
Medicine, Al-Azhar University, Cairo, Egypt.

\begin{abstract}
Background: Transcranial magnetic stimulation one of the tools that may help schizophrenic patients.

Aim of The Work: To Examine the validation of rTMS in treatment positive and negative symptoms of refractory schizophrenic patients.

Patients and Methods: The study included 40 resistance schizophrenic patients separated into two groups: Group A: 20 patients received 15 sessions of r-TMS for 3 weeks, With five daily sessions with a two day break, Group B: 20 patients were randomly (one every one patients) chosen for sham stimulation. The Positive and Negative Syndrome Scale was used to examine all patients before and after the intervention. Department of Psychiatry, Faculty of Medicine, Al-Azhar University, Cairo

Results: The mean age of all studied patients was $30.4 \pm 5.5$ years. 22 were males (55\%) and 18 females (45\%). The mean BMI of all studied patients was $28.7 \pm 3.01\left(\mathrm{~kg} / \mathrm{m}^{2}\right)$. The mean duration of disease was $11.45 \pm 6.3$ months. The mean age of onset was $18.9 \pm 2.4$ years. There were 9 patients $(22.5 \%)$ with positive family history. Active rTMS was accompanied by significant improvement in total PANSS degree, PANSS positive degree, PANSS negative degree and general psychopathology degree. The sham (placebo group) did not show any significant changes in schizophrenic symptoms (negative nor positive). Conclusion: Dual mode distribution rTMS stimulation of left DLPFC and left TPC could significantly improve schizophrenic patients with positive and negative symptoms.
\end{abstract}

Keywords: Resistant Schizophrenia; positive symptoms; negative symptoms; Transcranial Magnetic Stimulation.

Disclosure: The authors have no financial interest to declare in relation to the content of this article. The Article Processing Charge was paid for by the authors.

Authorship: All authors have a substantial contribution to the article.

\section{INTRODUCTION}

Schizophrenia has been described as a disease of brain connection, which is thought to constitute the pathophysiology of this sickness ${ }^{i}$.

Schizophrenia starts early in life and consequently reasons significant and long term disabilities. This requires continuous medical care, as well as rehabilitation and support services. The financial costs of the sickness in the United States have been estimated to be greater than the expenses for all cancers combined ${ }^{\mathrm{ii}}$.

Auditory hallucinations (AH) are one of the most common symptoms of schizophrenia, affecting 70 $80 \%$ of patients. They have been related to anatomical and/or physiological brain abnormalities in this disorderiii. Changes in the integrity of white matter in the left arcuate fascicle and inter hemispheric projections through the corpus callosum, for example, were linked to $\mathrm{AH}$ in schizophrenia patients in the structural domain ${ }^{\text {iv }}$.

Antipsychotics are efficacy in many cases, but they can also cause a lot of side effects like weight gain, sedation, increase serum prolactin, tardive dyskinesia and other movement disorders Furthermore, around $25 \%$ to $30 \%$ of patients recognized with schizophrenia not respond to antipsychotic medication ${ }^{\mathrm{v}}$

Repetitive Transcranial Magnetic Stimulation (rTMS) is a non-operative brain activation approach that has been found to be beneficial in the treatment of neuropsychiatric diseases including resistant depression, OCD, Neuropathic pain, autism, and migraine, among others ${ }^{1}$.

Few studies have lately tried it for the management of schizophrenia, with varying results ${ }^{2}$.

\section{PATIENTS AND METHODS}

This study was a Randomized interventional study conducted in Department of Psychiatry, Faculty of Medicine, Al-Azhar University

The study included forty patients who were schizophrenic according to standard of Diagnostic and Statistical Manual of Mental Disorders (DSM 5), which inclusive positive symptoms like hallucinations, delusions, and negative symptoms like poverty of motivation and lack of interest. Patients were selected randomly from the outpatient 
clinics of psychiatric department, Al-Azhar University.

The sufferers with schizophrenia were divided into 2 groups:-

Group A: Twenty patients received 15 sessions of $r$ TMS for 3 weeks, 5 days consecutive sessions and then two rest days.

Group B: Twenty patients were randomly (one every one patients) chosen

for sham stimulation (as a placebo group).

Patients will be selected according to the subsequent criteria:

\section{Inclusion criteria:}

All men and woman subjects, eighteen years of age or more.

Right-handed patients.

All patients were drug resistant. Treatment-resistant schizophrenia may be described on the basis of a few or a symptomatic response to double $(\geq 2)$ neuroleptic drug tests of a long enough ( $\geq$ six weeks) and at a therapeutic dose vary ${ }^{\mathrm{vi}}$.

All the patients studied were on their treatment throughout the study.

\section{Exclusion criteria:}

Previous date of CNS disease (like seizure) or head injury.

Un unstable medical condition

Patients who are difficult to communicate with them such as mental retardation, cognitive dysfunction, substance abuse.

Patients with a history of ECT therapy in the last 6 months

Left-handed patients.

Pregnant women.

\section{Clinical assessment}

The Positive and Negative Syndrome Scale was used to examine all patients before and after the intervention. PANSS was created to assess the degree of psychopathology in people who suffer from schizophrenia, schizoaffective disorder, and other psychotic illnesses. The belief in two different subtypes of schizophrenia provided the theoretical basis for the development of PANSS. Positive symptoms like delusions or hallucinations characterize Kind I, whereas negative symptoms like dulled emotion or social retreat characterize Kind II. The scale includes three Sections: Positive symptoms with 7 components, negative symptoms with 7 components, and a general psychopathology with 16 components. Each symptom is record on a sevenpoint scale (started with 1 to 7), PANSS grades started with 7 to 49 and the General Psychopathology Scale grades started with 16 to $112^{\text {vii }}$.

\section{Repetitive transcranial magnetic stimulation}

Twenty patients were treated by actual r-TMS and same number were subjected to sham stimulation as a group.

We utilized a Magstimrapid2 TMS machine (Magstim Ltd, Whitland, Wales) and a figure-ofeight coil to supply the r-TMS (diameter of each wing $70 \mathrm{~mm}$, peak magnetic field $2.2 \mathrm{~T}$ ). At the outset, we used the vision of movement to determine each patient's motor threshold. Motor threshold is defined as the less exciting stimulation able to causing an apparent finger movement by the abductor policies braves in at least 5 of 10 primary motor cortex stimulations ${ }^{\text {viii. }}$.

We used the International 10-20 technique used for EEG to identify the stimulation areas, naming the left dorsolateral prefrontal cortex (DLPFC) as F3 and the left TemporoParietal Cortex as the midway between T3 and P3. All patients had 15 r-TMS treatments over the course of three weeks, with five daily sessions separated by a two-day rest period. Each session had 40 trains that ran every 30 seconds: 20 trains of ten $\mathrm{Hz}$ r-TMS with a 3-s duration to the left DLPFC and 20 trains of one Hz r-TMS with a 30-s duration to the left TPC.

This approach included activating the left DLPFC with high-frequency energizing and the left TPC with low-frequency energizing ${ }^{\text {ix }}$.

The sham stimulation will be identically localized, with the coil oriented 90 degrees far from the skull. This approach produces intracerebral voltage around One third that of active TMS energizing while reproducing sound and a few body sensations (e.g. vibration and contraction of scalp muscles) that resemble active stimulation ${ }^{\mathbf{x}}$.

\section{Statistical analysis:}

Version 18.0 of the Statistical Program for the Social Sciences (SPSS) was utilized to analyze the data. Quantitative data were expressed as mean standard deviation (MSD), while qualitative data was expressed as frequency and percentage No ( percent), and the two were compared using the scholar t-test. To compare nonparametric data, the Chi-square test was used. Pvalues were calculated using a statistical significance of $P$ 0.05 .

\section{RESULTS}

\section{Baseline characteristics:}

As regard description of demographic and laboratory data, the average age of all studied patients was 30.4 \pm 5.5 years with least age of 21 years and most age of 42 years. 22 were males (55\%) and 18 females $(45 \%)$. The mean BMI of all studied patients was $28.7 \pm 3.01\left(\mathrm{~kg} / \mathrm{m}^{2}\right)$. The mean duration of disease was $11.45 \pm 6.3$ months. The mean age of onset was $18.9 \pm 2.4$ years. There were 20 smokers $(50 \%)$. There were 9 patients $(22.5 \%)$ with positive family history. 22 of studied patients were from rural $(55 \%)$ and 18 from urban $(45 \%)$.

There was no statistical significant difference (pvalue $>0.05$ ) between studied groups as regard demographic data (age, sex, duration, onset age, smoking, family history and residence). The baseline 
total PANSS grade of patients in the active r-TMS group $(78.4 \pm 16)$ and the placebo (sham) group (76.4 \pm 12.2$)$ was not significantly different (p-value $>0.05)$.

\section{Efficacy of rTMS}

Our study results showed that active rTMS had a significant impact in total PANSS degree, PANSS positive degree, PANSS negative degree and general psychopathology.

Among patients of active r-TMS group, the total PANSS score was $78.35 \pm 16$ and after treatment it became $51.8 \pm 12.8$ with highly statistical significant difference. The score of positive symptoms was $18.05 \pm 4.4$ before treatment and 13.5 \pm 6.08 after treatment. The negative symptoms were $26.05 \pm 6.16$ and became $15.55 \pm 5.18$ with highly statistical significant difference; the general psychopathology score was $34.25 \pm 15.22$ and became $22.75 \pm 9.54$.

Among patients of sham r-TMS group, the total
PANSS score was $76.4 \pm 12.2$ and after treatment it became $73.9 \pm 12.5$. The score of positive symptoms was $19.2 \pm 5.5$ before treatment and $17.9 \pm 4.9$ after treatment. The negative symptoms were $24.2 \pm 7.0$ and became $23.60 \pm 6.8$; the general psychopathology score was $33.1 \pm 6.8$ and became $32.4 \pm 6.5$, the difference was not significant in all. patients $(50 \%)$, and one "severe" patient (12.5\%).

In female patients with hand pain $(\mathrm{n}=36)$, Kellegren Lawrence class was mild (grade II) in eight patients $(22.2 \%)$, moderate (grade III) in 21 patients $(58.3 \%)$ and severe (grade IV) in seven patients $(19.4 \%)$. There were morphological changes in four "mild" patients (11.1\%), 13 "moderate" patients (36.1\%) and four "severe" patients $(11.1 \%)$. There was low capillary density in 5 "mild" patients (13.9\%), 17 "moderate" patients (47.2\%) and 5 "severe" patients (13.9\%).

So, there were about 41 patients $(73.2 \%)$ with low capillary density in all studied patients.

\begin{tabular}{|c|c|c|c|}
\hline & & \multicolumn{2}{|c|}{ Studied patients $(\mathrm{N}=40)$} \\
\hline \multirow[t]{2}{*}{ Age (years) } & Mean \pm SD & \multicolumn{2}{|c|}{$30.4 \pm 5.5$} \\
\hline & Min - Max & \multicolumn{2}{|c|}{$21-42$} \\
\hline \multirow[t]{2}{*}{ Sex } & Male & 22 & $55 \%$ \\
\hline & Female & 18 & $45 \%$ \\
\hline \multirow[t]{2}{*}{ BMI $\left(\mathbf{k g} / \mathbf{m}^{2}\right)$} & Mean \pm SD & \multicolumn{2}{|c|}{$28.7 \pm 3.01$} \\
\hline & Min - Max & \multicolumn{2}{|c|}{$22-33$} \\
\hline \multirow[t]{2}{*}{ Duration of disease (months) } & Mean \pm SD & \multicolumn{2}{|c|}{$11.45 \pm 6.3$} \\
\hline & Min - Max & \multicolumn{2}{|c|}{$3-24$} \\
\hline \multirow[t]{2}{*}{ Age of onset (years) } & Mean \pm SD & \multicolumn{2}{|c|}{$18.9 \pm 2.4$} \\
\hline & Min - Max & \multicolumn{2}{|c|}{$15-24$} \\
\hline \multirow[t]{2}{*}{ Smoking } & No & 20 & $50 \%$ \\
\hline & Smoker & 20 & $50 \%$ \\
\hline \multirow[t]{2}{*}{ Family history } & Negative & 31 & $77.5 \%$ \\
\hline & Positive & 9 & $22.5 \%$ \\
\hline \multirow[t]{2}{*}{ Residence } & Rural & 22 & $55 \%$ \\
\hline & Urban & 18 & $45 \%$ \\
\hline
\end{tabular}

Table 1: Description of demographic data in studied groups

\begin{tabular}{ccccc}
\hline \multicolumn{1}{c}{ (Pre rTMS) } & & Cases $(\mathbf{N}=\mathbf{2 0})$ & Sham $(\mathbf{N}=20)$ & P-value \\
\hline $\begin{array}{c}\text { General } \\
\text { psychopathology }\end{array}$ & Mean & 34.3 & 33.1 & 0.749 NS \\
\hline Negative symptoms & \pm SD & 15.2 & 6.8 & \\
& Mean & 26.1 & 24.2 & 0.379 NS \\
Positive symptoms & \pm SD & 6.2 & 7.0 & 0.488 NS \\
& Mean & 18.1 & 19.2 & \\
Total PANSS & \pm SD & 4.4 & 5.5 & 0.668 NS \\
\hline
\end{tabular}

Table 2: comparison between studied groups as regard Pre rTMS Clinical assessment.

This table shows no statistical significant difference ( $\mathrm{p}$-value $>0.05$ ) between studied groups as regard Pre rTMS

Clinical assessment (General psychopathology, negative symptoms, positive symptoms and total PANSS). 


\begin{tabular}{|c|c|c|c|c|}
\hline \multicolumn{2}{|c|}{ (Cases group) } & \multirow{2}{*}{$\begin{array}{c}\text { Pre }(\mathbf{N}=\mathbf{2 0}) \\
34.25\end{array}$} & \multirow{2}{*}{$\begin{array}{c}\text { Post }(\mathbf{N}=\mathbf{2 0}) \\
22.75\end{array}$} & \multirow{3}{*}{$\begin{array}{l}\text { P-value } \\
0.007 \mathrm{~S}\end{array}$} \\
\hline General & Mean & & & \\
\hline & $\pm \mathrm{SD}$ & 15.22 & 9.54 & \\
\hline \multirow[t]{2}{*}{ Negative symptoms } & Mean & 26.05 & 15.55 & $<0.001 \mathrm{HS}$ \\
\hline & $\pm \mathrm{SD}$ & 6.16 & 5.18 & \\
\hline \multirow[t]{2}{*}{ Positive symptoms } & Mean & 18.05 & 13.50 & $0.01 \mathrm{~S}$ \\
\hline & $\pm \mathrm{SD}$ & 4.43 & 6.08 & \\
\hline \multirow[t]{2}{*}{ Total PANSS } & Mean & 78.35 & 51.80 & $<0.001 \mathrm{HS}$ \\
\hline & $\pm \mathrm{SD}$ & 16.04 & 12.83 & \\
\hline
\end{tabular}

Table 3: Comparison of Pre and post active rTMS Clinical assessment in Cases group.

This table shows statistical significant difference (p-value $<0.001)$ between Pre and post active rTMS Clinical assessment in Cases group.

\begin{tabular}{|c|c|c|c|c|}
\hline \multicolumn{2}{|c|}{ (Sham group) } & \multirow{2}{*}{$\begin{array}{c}\text { Pre }(\mathrm{N}=20) \\
33.1\end{array}$} & \multirow{2}{*}{$\begin{array}{c}\text { Post }(\mathbf{N}=20) \\
32.4\end{array}$} & \multirow{2}{*}{$\begin{array}{c}\text { P-value } \\
0.759 \mathrm{NS}\end{array}$} \\
\hline General & Mean & & & \\
\hline & $\pm \mathrm{SD}$ & 6.8 & 6.5 & \\
\hline \multirow[t]{2}{*}{ Negative symptoms } & Mean & 24.2 & 23.6 & $0.767 \mathrm{NS}$ \\
\hline & $\pm \mathrm{SD}$ & 7.0 & 6.8 & \\
\hline \multirow[t]{2}{*}{ Positive symptoms } & Mean & 19.2 & 17.9 & $0.452 \mathrm{NS}$ \\
\hline & $\pm \mathrm{SD}$ & 5.5 & 4.9 & \\
\hline \multirow[t]{2}{*}{ Total PANSS } & Mean & 76.4 & 73.9 & $0.518 \mathrm{NS}$ \\
\hline & $\pm \mathrm{SD}$ & 12.2 & 12.5 & \\
\hline
\end{tabular}

Table 4: Comparison of Pre and post active rTMS Clinical assessment in Sham group.

This table shows no statistical significant difference ( $\mathrm{p}$-value $>0.05$ ) between Pre and post sham rTMS Clinical assessment.

\section{DISCUSSION}

Our study outcomes confirmed that active rTMS was linked with significant improvement in total PANSS degree, PANSS positive degree, PANSS negative degree and general psychopathology degree.

In agreement with the current study, Oh and Kim used the identical r-TMS protocol as the present study and they found that r-TMS was effective in decreasing the total degree of PANSS and degree of the positive and negative subscale. ${ }^{11}$

Results obtained in this study were resemble with Poulet et al. who conducted a double-blind study of ten patients with treatment resistant auditory hallucinations. $^{12}$
In a current meta-analysis by $\mathrm{He}$ et al. who did thirteen studies for evaluation, and similarly detected a modest impact for $1-\mathrm{Hz}$ rTMS on auditory hallucinations in schizophrenic patients. ${ }^{13}$

In contrast to our results, Fitzgerald et al. found no difference in therapeutic effect in the domains between the real and sham groups of twenty patients complaining from modest to sharp resistant negative symptoms. ${ }^{14}$

Similarly, Saba et al. used TMS for 10 days to treat eighteen schizophrenia patients with persistent auditory hallucinations. There were no beneficial between the impact and placebo groups, according to the researchers. ${ }^{15}$

In 2011, a number of randomized experiments utilizing fMRI to determine TMS treatment location 
did not show any improvement in the intensity of auditory hallucinations. ${ }^{16}$

In agreement with this study, a sham-controlled trial was performed by Hajak et al. on twenty schizophrenia patients who obtained high frequency TMS to the left dorsolateral prefrontal cortex over ten days. Functional neuroimaging was done at the conclusion of the research; there was a significant decrease in negative and depressed symptoms, but no changes in neuroimaging were reported. ${ }^{17}$

In another recent study from our locality, by Nagy et al. who led to a Randomized interventional research on forty patients with schizophrenia. There was statistical significance differences between active and sham group as regarding PANSS Negative subdomain scale, used prior and after the rTMS sessions $(\mathrm{P}$ value $=0.001){ }^{18}$

In contrast to our results, numerous different clinical studies haven't supported validation of rTMS in the management of negative symptoms of schizophrenic patients.

A meta-analysis conducted through Freitas et al comprising eight high frequency $(10 \mathrm{~Hz})$ stimulus studies practice to the left dorsolateral prefrontal part of the cortex in schizophrenia patients with seen an impact length of $0.58 .^{19}$

Another meta-analysis looked at seven highfrequency controlled trials on schizophrenia patients' left dorsolateral prefrontal cortex and found an effect size of 0.63 . TMS effect sizes range from 0.27 to 0.63 , which is positive; given that effect sizes for neuroleptic drug therapy of bad symptoms range from 0.17 to 0.21 . $^{20}$

\section{CONCLUSION}

Dual mode distribution to rTMS energizing of both left DLPFC and left TPC could be significantly improve positive and negative symptoms in resistant schizophrenic patients.

\section{REFERENCES}

1. Yan, T., Xie, Q., Zheng, Z., Zou, K., \& Wang, L. Different frequency repetitive transcranial magnetic stimulation (rTMS) for posttraumatic stress disorder (PTSD): a systematic review and metaanalysis. Journal of psychiatric research. 2017; 89, 125-35.

2. Kumar, N., Vishnubhatla, S., Wadhawan, A. N., Minhas, S., \& Gupta, P. A randomized, double blind, sham-controlled trial of repetitive transcranial magnetic stimulation (rTMS) in the treatment of negative symptoms in schizophrenia. Brain stimulation. 2020; 13(3), 840-9.

3. Paillere-Martinot, M.L., Galinowski, A., Plaze, M., Andoh, J., Bartres-Faz, D., Bellivier, F., Lefaucheur, J.P., Riviere, D., Gallarda, T., Martinot, J.L., Artiges, E. Active and placebo transcranial magnetic stimulation effects on external and internal auditory hallucinations of schizophrenia Acta Psychiatrica Scandinavica. 2017; 135 (3), 228-8.

4. Thomas, F., Moulier, V., Valéro-Cabré, A., Januel, D. Brain connectivity and auditory hallucinations: in search of novel noninvasive brain stimulation therapeutic approaches for schizophrenia. Rev. Neurol. (Paris). 2016; 172 (11), 65379.

5. Li, J., Cao, X., Liu, S., Li, X., \& Xu, Y. Efficacy of repetitive transcranial magnetic stimulation on auditory hallucinations in schizophrenia: A metaanalysis. Psychiatry Research. 2020; 290, 113141.

6. Lehman, A. F., Kreyenbuhl, J., Buchanan, R. W., Dickerson, F. B., Dixon, L. B., Goldberg, et al. The schizophrenia patient outcomes research team (PORT): Updated treatment recommendations 2003. Schizophrenia bulletin. 2004; 30(2), 193-217.

7. Kay, S.R., Fiszbein, A. and Opler, L.A. The positive and negative syndrome scale (PANSS) for schizophrenia. Schizophrenia bulletin. 1987; 13(2), pp.261-76.

8. Pridmore S, Fernandes Filho JA, Nahas Z, Liberatos C, George MS. Motor threshold in transcranial magnetic stimulation: a comparison of a neurophysiological method and a visualization of movement method. The Journal of ECT. 1998; $14: 25-7$.

9. Chouinard PA, Van Der Werf YD Leonard G and Paus $T$. Modulating neural networks with transcranial magnetic stimulation applied over the dorsal premotor and primary motor cortices. Journal of Neurophysiology. 2003; 90(2), pp.1071-83.

10. Lisanby, S. H., Gutman, D., Luber, B., Schroeder, C., \& Sackeim, H. A. Sham TMS: intracerebral measurement of the induced electrical field and the induction of motor-evoked potentials. Biological psychiatry, 2001; 49(5), 460-3

11. Oh, S. Y., \& Kim, Y. K. Adjunctive treatment of bimodal repetitive transcranial magnetic stimulation (rTMS) in pharmacologically non-responsive patients with schizophrenia: a preliminary study. Progress in Neuro-psychopharmacology and Biological Psychiatry. 2011; 35(8), 1938-43

12. Poulet, E., Brunelin, J., Bediou, B., Bation, R., Forgeard, L., Dalery, J., et al. Slow transcranial magnetic stimulation can rapidly reduce resistant auditory hallucinations in schizophrenia. Biological psychiatry. 2005; 57(2), 188-91.

13. He, H., Lu, J., Yang, L., Zheng, J., Gao, F., Zhai, Y., Feng, J., Fan, Y., Ma, X. Repetitive transcranial magnetic stimulation for treating the symptoms of schizophrenia: a PRISMA compliant meta-analysis. Clinical Neurophysiology. 2017; 128 (5), 716-24.

14. Fitzgerald, P. B., Herring, S., Hoy, K., McQueen, S., Segrave, R., Kulkarni, J., \& Daskalakis, Z. J. A study of the effectiveness of bilateral transcranial magnetic stimulation in the treatment of the negative symptoms of schizophrenia. Brain Stimulation. 2008; 1(1), 27-32.

15. Saba, G., Verdon, C. M., Kalalou, K., Rocamora, J. F., Dumortier, G., Benadhira, R., et al. Transcranial 
magnetic stimulation in the treatment of schizophrenic symptoms: a double blind sham controlled study. Journal of psychiatric research. 2006; 40(2), 147-52.

16. Slotema, C. W., Blom, J. D., de Weijer, A. D., Diederen, K. M., Goekoop, R., Looijestijn, J., et al. Can low-frequency repetitive transcranial magnetic stimulation really relieve medication-resistant auditory verbal hallucinations? Negative results from a large randomized controlled trial. Biological psychiatry. 2011; 69(5), 450-6.

17. Hajak, G., Marienhagen, J., Langguth, B., Werner, S., Binder, H., \& Eichhammer, P. High-frequency repetitive transcranial magnetic stimulation in schizophrenia: a combined treatment and neuroimaging study. Psychological medicine. 2004; 34(7), 1157-63.

18. Nagy, N., El Ghoniemy, S., Kito, S., El Missiry, M., ElKholy, H., \& Yousry, S. PRELIMINARY STUDY ON THE EFFECT OF REPETITIVE TRANSCRANIAL MAGNETIC STIMULATION ON NEGATIVE SYMPTOMS IN PATIENTS WITH SCHIZOPHRENIA. Ain Shams Medical Journal. 2019; 70(4, 5 \& 6), 307-14.

19. Freitas, C., Fregni, F., \& Pascual-Leone, A. Metaanalysis of the effects of repetitive transcranial magnetic stimulation (rTMS) on negative and positive symptoms in schizophrenia. Schizophrenia research. 2009; 108(1-3), 11-24.

20. Dlabač-de Lange, J. J., Knegtering, R., \& Aleman, A. Repetitive transcranial magnetic stimulation for negative symptoms of schizophrenia: review and meta-analysis. The Journal of clinical psychiatry. 2010; 71(4), 0-0. 